\title{
Determinants of Technical Efficiency of Maize Production in Ethiopia: An Empirical Review
}

\author{
Firomsa Mersha Tekalign \\ School of Agricultural Economics and Agribusiness, Haramaya University, Haramaya, Ethiopia \\ Email address: \\ firomer2008@gmail.com \\ To cite this article: \\ Firomsa Mersha Tekalign. Determinants of Technical Efficiency of Maize Production in Ethiopia: An Empirical Review. American Journal \\ of Environmental and Resource Economics. Special Issue: Agricultural Economics and Rural Development. \\ Vol. 4, No. 4, 2019, pp. 144-151. doi: 10.11648/j.ajere.20190404.15
}

Received: September 25, 2019; Accepted: November 6, 2019; Published: November 19, 2019

\begin{abstract}
Ethiopia is an agrarian country where a large majority of the peoples and the poor living in rural areas are deriving their livelihood from agriculture. However, low levels of agricultural productivity and increasing population pressure have been critical problems of Ethiopia. These have aggravated the food insecurity situation by widening the gap between demand for and supply of food. In Ethiopia, information on the levels of productivity of maize and farm household technical efficiency in its production is lacking. This paper is aiming at reviewing the major determinants of technical efficiency of maize in Ethiopia using meta-analysis method. Increasing efficiency in maize production could be taken an important step towards attaining food security. The meta-analysis results revealed that important factors that affects the technical efficiency of maize production in Ethiopia were age, family size, education, land holding, livestock ownership, off-farm income, access to credit, contact with extension workers and distance from the nearest market. Many Literatures also suggests the factors that affect the efficiency variation of smallholder farmers classifying them into different categories. These (in) efficiency factors are classified into demographic such as age and family size; socio-economic like education, land holding, livestock ownership, and off-farm income; institutional factors such as access to credit, and contact with extension workers; and physical factor like distance from the nearest market. Therefore, designing and implementing an appropriate policy intervention by focusing on the abovementioned factors is important in Ethiopia.
\end{abstract}

Keywords: Determinants, Technical Efficiency, Maize, Production, Ethiopia

\section{Introduction}

Ethiopia is an agrarian country where a large majority of peoples and the poor living in rural areas are deriving their livelihood from this agriculture. Smallholder farming households, which cultivated $94 \%$ of the national cropped area in 2013/14, dominates it [1]. Although the transformation towards a more manufacturing and industrially oriented economy is well underway, the agriculture sector continues to be the most dominant aspect of the Ethiopian economy, accounting for nearly $46 \%$ of GDP, $73 \%$ of employment, and nearly $80 \%$ of foreign export earnings [2].

Growth in agriculture from the crop production sub-sector, cereals are the dominant food grains. Within agriculture, $50 \%$ of the output of agricultural GDP comes from crop production whereas, $47 \%$ and $3 \%$ are from livestock and forestry respectively. The major crops occupy over 8 million hectares of land with an estimated annual production of about 12 million tons [3]. The potential to increase productivity of these crops is very high as it has been demonstrated and realized by recent extension activities in different parts of the country. However, population expansion, low productivity due to lack of technology transfer and decreasing availability of arable land are the major contributors to the current food shortage in Ethiopia [4].

The Report indicated that there was an increase in total food grain production from 58,505.42 tons in 1988/89 to 203.48 million tons in $2010 / 2011[5,6]$. However, this increment in output could not be attributed to improvement in productivity alone as there was simultaneous increase in the size of cultivated land from 4.99 million ha to 11.82 million ha in the same period. However, the future cereal production growth need to come increasingly from yield 
improvements as there is little suitable land available for the expansion of crop cultivation in the country, especially in the highlands [7].

Maize is one of the cereal crop produced in most part of Ethiopia. In 2007/08, maize production was 42 million qt, 40 percent higher than teff and 75 percent higher than wheat production. With an average yield of 17.4 qt per hectare (equal to 32 million qt grown over 1.8 million hectares) from 1995 to 2008, maize has been the leading cereal crop in Ethiopia since the mid-1990s in terms of both crop yield and production [8]. In the year 2008/09, cereals contributed $84.69 \%$ (about 144.96 million $\mathrm{qt}$ ) of the grain production in Ethiopia. From which maize, wheat, teff and sorghum made up $22.97 \%$ (39.32million qt), $14.83 \%$ (25.37 million qt), $17.69 \%$ (30.28 million $\mathrm{qt})$ and $16.38 \%$ (28.04 million $\mathrm{qt})$ of the grain production, respectively. The average yield of cereals namely maize, wheat and teff were 22.24, 17.46 and 12.22 qt per hectare, respectively [9].

In 2010/11 production year, maize covered 1.96 million ha of land at country level (about $17 \%$ of the total area covered by all crops). The total output of maize in the same year at country level was 49.86 million qt that is $24.5 \%$ of the total crop production in the same year [5].

Notwithstanding agricultural production improvements through different development interventions, efficiency of cereal crops at farm levels are still in its low-level productivity for the majority of smallholder farmers. This was reasoned out as poor farmers' Perception towards new technologies, poor targeting of policy makers and research institutions to deliver appropriate and demand driven technologies. As a result, the average national crop and livestock productivity silent remained far below its potential in Sub-Saharan average [10]. Although most research outputs (technologies) are superior for terms of their productivity and their economic return, there might be some exceptional cases where the new technologies may not be compatible to the farmers' situations.

A study shows that access and better use of modern agricultural technology and agricultural inputs have effect on production and productivity by enhancing efficiency gain $[11,12]$. However, provision of improved agricultural technology is a supply side issue for smallholder farmers, understanding end users capacity and demand to adopt the technology will have immense contribution in the problem of productivity and technical efficiency of the beneficiaries under consideration.

Ethiopian Smallholder farmers are known to work under resource endowments [13], different farming practices knowledge, cultural practices and socio-economic conditions. These in turn, have resulted in farm level technical efficiency variation and understanding household level technical efficiency influencing factors has overriding connotations for country's choice of development inputs and outputs policies and strategy [14]. Since most of the development interventions are targeted towards the neediest segment of the society, the effort to enhance productivity and efficiency is expected to have a very far-reaching impact in bring livelihood improvement.

The current average productivity of cereal crops in general and maize productivity in particular of Ethiopia at national level (which is 32.54 quintal per ha) is better than the national productivity of many African countries. The studies on the output of maize production in Ethiopia found low efficiency in comparison with the world maize productivity (which is 50 quintal per ha) $[15,16]$. Besides, spatial variability in maize productivity is another concern for maize productivity enhancement in Ethiopia.

In Ethiopia, information on the levels of productivity of maize and farm household technical efficiency in its production is lacking. Therefore, in order to improve maize production and productivity, an efficient use of production inputs has to be adopted by smallholder farmers. Thus, identifying the determinants of production levels and reducing its variability are both essential aspects to improve food security and well-being of the people of Ethiopia.

Therefore, the main objective of this paper is to review the technical efficiency and its determinants on maize production in Ethiopian.

\section{Measures and Techniques to Technical Efficiency}

\subsection{Theoretical Measures of Technical Efficiency}

Farrell was a famous scholar who introduces the first analyses of efficiency measures after dividing it into two components: technical and allocative/price efficiency. Technical efficiency shows firm's ability to produce a maximum level of output from a given level of inputs, whereas allocative/price efficiency presents the ability of a firm to use inputs in optimal proportions, given their prices and existing technology. The sum of the two yields the level of economic efficiency (overall efficiency). Technical efficiency value will take a value between zero and one showing the extent of technical in/efficiency of the production unit. As value approaches to one, the firm will approaches to technically efficient point [17].

\subsection{Techniques for Estimation of Technical Efficiency}

There are two main approaches used to construct efficiency frontiers, parametric and non-parametric approaches. Non-parametric approach estimation method is based on data envelopment analysis (DEA), which is developed Farrell, in this method, the estimation of technical efficiency is based on linear programming and consists of estimated a production frontier through a convex envelope curve formed by line segments joining observed efficient production units. No functional form is imposed on the production frontier and no assumption is made on the error term. This method has used in many literatures and it is criticized on four big points. Firstly, one cannot test for the best specification; secondly, it does not take measurement errors and random effects into account; thirdly, the number of 
efficient firms on the frontier tends to increase with the number of inputs and output variables and fourthly, results are sensitive to the selection of inputs and outputs.

The parametric approach, which was independent and simultaneous work of Aigner et al., and Meeusen and J.van, can produce stochastic frontier production function unlike the non-parametric method of estimating efficiency $[18,19]$.

The parametric approach enables us to test for the best specification and take measurement errors and random effects into account during estimation of efficiency level of the firm. This method also called composed error approach. Thus, any deviation from efficient frontier for a firm is not only because of measurement error but also because of management inefficiency of the firm. Unlike non-parametric approach, it depends on econometric estimation procedure. However, parametric approach further specified in two types.

A. The deterministic parametric Approach to technical Efficiency Measurement

The deterministic parametric approach of technical efficiency measurement with the aid of Cobb-Douglass production function computing parametric convex hull of actual observed input-output ratios. This method of estimation assumes that any deviation from the estimated frontier is due to inefficiency [17]. It is presented as,

$$
Y_{i}=f\left(X_{i}, \beta\right) e^{\left(-U_{i}\right)}, i=1,2, \ldots, N
$$

Where;

$Y_{i}$ - The output level for ith producer;

$\mathrm{X}_{\mathrm{i}}$-is a vector of inputs used in the production process for ith producer and

$\beta-$ is a vector of unknown parameter estimates; $U_{i}-$ is non-negative random variable representing technical inefficiency associated with production of producer $i$, independently and identically distributed (i.i.d) as $\mathrm{N} \sim\left(0, \delta_{\mathrm{u}}^{2}\right)$ and $\mathrm{e}^{\left(-\mathrm{U}_{\mathrm{i}}\right)}$ - is the technical inefficiency in production and $\mathrm{N}$ - represents the number of producers involved in crosssectional survey. Since the value for $\mathrm{e}^{\left(-\mathrm{U}_{\mathrm{i}}\right)}$ lies between zero and one, the possible production $\left(\mathrm{Y}_{\mathrm{i}}\right)$ bounded from the above by the deterministic (non-stochastic) quantity, $f\left(X_{i}, \beta\right)$ i.e

$$
Y_{i} \leq f\left(X_{i}, \beta\right), i=1,2, \ldots, N
$$

Equation (2) above specified as linear or quadratic algorithms determined the unknown parameters. The inequality restrictions show that the production could be permitted to lie above the estimated frontier, which in turn results in the problem of outliers lacking statistical or economic rationale. This made this mode of estimating technical efficiency level of producers as criticized on this ground [20].

B. The Stochastic Production Frontiers Approach

i. One output - multiple input case cross-sectional model of technical efficiency.

The estimation of the frontier production function was the first work of Aigner et al., and Meeusen and J.van. It is implemented with the acknowledgment of the theoretical restraint that all observations lie below it, and it is generally a means to another end than an end to another end. Therefore, the stochastic estimation of technical efficiency accounts for the measurement of the random error term (uncontrollable factors) and the misperformances of the producer (systematic factors that believed to be source of technical inefficiency). This implies that the specification of the model involves composed error term with two elements. The model for a one output- multiple inputs case can be represented by:

$$
\begin{array}{r}
Y_{\mathrm{i}}=\mathrm{f}\left(\mathrm{X}_{\mathrm{i}}, \beta\right) \mathrm{e}^{\left(\varepsilon_{\mathrm{i}}\right)} \\
\text { where } \varepsilon_{i}=v_{i}-u_{i}
\end{array}
$$

Where

$Y_{i}$ - The amount of maize or sorghum of the ith farm household in the sample,

$f\left(X_{i}, \beta\right)-$ The deterministic component of the production function,

$\mathrm{X}_{\mathrm{i}}^{\prime} s-$ Vectors of inputs used in the production process by ith farmer,

$\beta^{\prime}$ s - Vector of unknown parameters to be estimated and $\varepsilon_{i}-$ The composite error term i.e. $\varepsilon_{i}=v_{i}-u_{i}$.

As stated above $v_{i}$ - all factors outside the farmer's control accounts for statistical noise and assumed to be IID as $\mathrm{Vi} \sim\left(0, \delta_{\mathrm{v}}^{2}\right)$; and $\mathrm{u}_{\mathrm{i}}-$ is shortfall of actual output from its maximum potential possible output and assumed to be nonnegative truncation of $\mathrm{Ui} \sim\left(0, \delta_{\mathrm{u}}^{2}\right)$ distribution i.e. normal-half distribution. That is, the probability density function (p.d.f) of each $\mathrm{Ui}$ is a truncated version of a normal random variable having zero mean and variance $\delta_{\mathrm{u}}^{2}$.

If one of the two error terms left out of the model, we will end up with one of the following models than having stochastic frontier model. These are;

a) Deterministic frontier production function model, if

$$
v_{i}=0 \text { for all } i \text {, then } \mathrm{Y}_{\mathrm{i}}=\mathrm{f}\left(\mathrm{X}_{\mathrm{i}}, \beta\right) \mathrm{e}^{\left(-\mathrm{U}_{\mathrm{i}}\right)} .
$$

That is any deviation of actual observed output from the maximum possible output is because of misperformances of the producer than any other factors outside producers control.

b) Stochastic production function model, if $u_{i}=$ 0 for all $i$, then

$Y_{i}=f\left(X_{i}, \beta\right) e^{\left(-v_{i}\right)}$. This on the other hand shows that any deviation in actually observed output from the maximum possible output is because of statistical noise than any other producer specific factors.

Technical efficiency estimation of the producer under this method also follows the usual techniques of computing TE that consistent with the theoretical estimation technique i.e. the ratio of observed output to the corresponding frontier output. The econometric version of the Debreu-Farrell output-oriented estimation of technical efficiency with its reciprocal can be given as follow;

$$
\mathrm{TE}_{\mathrm{i}}=\frac{\mathrm{Y}_{\mathrm{i}}}{\mathrm{f}\left(\mathrm{X}_{\mathrm{i}}, \beta\right) \mathrm{e}^{\left(\mathrm{v}_{\mathrm{i}}\right)}}=\frac{\mathrm{f}\left(\mathrm{X}_{\mathrm{i}}, \beta\right) \mathrm{e}^{\left(\varepsilon_{\mathrm{i}}\right)}}{\mathrm{f}\left(\mathrm{X}_{\mathrm{i}}, \beta\right) \mathrm{e}^{\left(\mathrm{v}_{\mathrm{i}}\right)}}=\frac{1}{\mathrm{e}^{\mathrm{v}_{\mathrm{i}}}}=\mathrm{e}^{-\mathrm{v}_{\mathrm{i}}}
$$

Where $\mathrm{TE}_{\mathrm{i}} \in(0,1)$ represents the efficiency score for ith producer and unit values shows that producer is fully technically efficient.

ii. Estimation techniques of technical efficiency 
If $v_{i}=0$, the deterministic frontier production function model can be estimated by using the following three techniques:

a. Corrected ordinary least squares: Since this method estimates unknown parameters by using OLS after transforming production function in to the natural logarithm, any assumption concerning the functional form $u_{i}$ does not matter. Because of the fact that composed error term is asymmetric, OLS estimation fails yield BLUE estimators i.e. $\varepsilon_{i}=v_{i}-u_{i} \neq 0$. Therefore, it is impossible to decompose the technical inefficiency from the statistical disturbance with OLS.

$$
E\left(\epsilon_{i}\right)=E\left(v_{i}\right)-E\left(u_{i}\right)=0-E\left(u_{i}\right)=-E\left(u_{i}\right)<0
$$

b. Modified Ordinary Least Squares: Incorporates the functional form of the $u_{i}$ (such as normal, truncated, exponential, etc.). Initially $\beta^{\prime} s$ were estimated from the already transformed production function i.e.

$\ln Y_{i}=\ln f\left(X_{i}, \beta\right)+v_{i}-u_{i}$ Then estimates intercept by shifting it up by minus the estimated mean of, which is extracted for OLS residuals. In the next step, these residuals modified in opposite direction and entered into equation (2.4) to estimate technical efficiency level of producer. However, this estimation technique was criticized on the shifting up of the intercept to cover all observation and its possibility to undergo such step i.e. it may yield $T E_{i}>1$ for some observation which very difficult to forward economic justifications for them.

c. Maximum Likelihood Estimator (MLE): this estimation technique takes the distributional assumption of in account and unknown parameters are simultaneously estimated. MLE envelops all observations and then the computed residuals are entered into equation (4) for the estimation of $T E_{i}$. This method satisfies all necessary constraint condition explained in the theoretical measurement of technical efficiency i.e. $0<T E_{i}<1$.

\section{Methodology}

The sources of information for this review are mainly secondary. Many government and non-government agencies have produced reports on agricultural output growth in Ethiopia. As much as possible, all these sources have been used to assess the current crop production growth and contribution of maize in specific. Published article and books references were searched for the review of technical efficiency of maize production in Ethiopia. Two methods of identifying the major determinants of technical efficiency were used.

\subsection{Identifying the Most Frequently Significant Variables from the Literature}

In this method is identifying what many literatures suggests as factors that affect the efficiency variation (determinants of technical efficiency of maize production) of smallholder farmers classifying them into different categories and analyzing them were employed. These (in) efficiency factors are classified into demographic (such as age, family size, etc.), socio-economic (like education, land holding, livestock ownership, off-farm income, etc.), institutional factors (access to credit, Membership of social organization, contact with extension workers, etc.) and physical factor (distance from the nearest market).

\subsection{The Random Effect Model Estimation (Meta-Analysis Method)}

The statistical methods are generally based on standard fixed or random effects models. The random effects model is discussed as follow.

Consider a collection of $\mathrm{k}$ studies, the $i^{\text {th }}$ of which has estimated effect size $Y i$ and true effect size $\theta$ i. A general model is then specified by:

$$
Y_{i}=\theta_{i}+e_{i}(6)
$$

where $e_{i}=^{d} N\left(0, \sigma_{i}^{2}\right), i=1,2,3, \ldots k$

The $e i$ indicate random deviations from the true effect size and are assumed independent with mean zero and variance $\delta^{2}$ i. This implies that the estimated effect size $Y i$ is normally distributed with mean $\theta \mathrm{i}$ and variance $\delta^{2}$ i. $Y i$ can be any measure of effect, provided the assumption of normality is (at least approximately) appropriate. Common examples are a log-odds ratio or difference in means.

In general the parameter of interest is the overall effect, denoted by $\mu$. the fixed effects model assumes $\theta \mathrm{i}=\mu$ for $\mathrm{i}=$ $1,2 \ldots \mathrm{k}$, implying that each study in the meta-analysis has the same underlying effect. Note that even if $\theta \mathrm{i}$ are assumed to be the same, the $Y i$ are not identically distributed due to the possibility of differing $\delta^{2}$ i. The estimator of $\mu$ is generally a simple weighted average of the $Y i$, with the optimal weights proportional to $w_{i}=1 /$ var (Yi). In practice the variances are not known so estimated variances $\delta^{\wedge} 2 \mathrm{i}$ are used to estimate both $\mu$ and $\operatorname{var}\left(\mu^{\wedge}\right)$. Any effect of this is generally ignored in practice, but to indicate this estimation we use the notation $\delta$ ${ }^{\wedge} 2 \mathrm{i}$ throughout. Hence we define $\mathrm{w}^{\wedge} \mathrm{i}=1 / \delta^{\wedge} 2$ i giving:

$$
\hat{\mu}=\frac{\sum \widehat{w}_{i} Y_{i}}{\sum \widehat{w}_{i}}=\frac{\sum \frac{Y_{i}}{\widehat{\sigma}_{i}^{2}}}{\sum \frac{1}{\hat{\sigma}_{i}^{2}}} \text { and } \widehat{\operatorname{var}}(\hat{\mu})=\frac{1}{\sum \frac{1}{\widehat{\sigma}_{i}^{2}}}
$$

In contrast to the fixed effects model, the random effects model does not assume that $\theta \mathrm{i}$ are equal, but that they are normally distributed. This gives the two-stage model

$$
\begin{aligned}
& Y_{i}=\theta_{i}+e_{i} \text { where } e_{i}={ }^{d} N\left(0, \hat{\sigma}_{i}^{2}\right) \\
& \theta_{i}=\mu_{i}+\varepsilon_{i} \text { where } \varepsilon_{i}={ }^{d} N\left(0, \tau^{2}\right)
\end{aligned}
$$

The error terms ei and $\varepsilon$ i are assumed to be independent. In this case, the true effect for study $i$ is centered on the overall effect, allowing individual studies to vary both in estimated effect and true effect. The random effects variance parameter $\tau^{2}$ is a measure of the heterogeneity between studies. The fixed effects model is a special case of the random effects model, with $\tau^{2}=0$.

The random effects model given in (1) can be written: 


$$
Y_{i}=\mu+\varepsilon_{i}+e_{i}
$$

where $e_{i}={ }^{d} N\left(0, \hat{\sigma}_{i}^{2}\right)$ and $\varepsilon_{i}={ }^{d} N\left(0, \tau^{2}\right)$

Relating the $Y i$ directly to the overall measure of effect $\mu$. By the independence of $\varepsilon_{i}$ and $\mathrm{e}_{\mathrm{i}}$ we then have $Y_{i}={ }^{d} N\left(0, \hat{\sigma}_{i}^{2}+\tau^{2}\right)$.

A weighted average is again used to estimate $\mu$, giving: $\hat{\mu}_{\tau}$ $=\frac{\sum \widehat{w}_{i}(\tau) Y_{i}}{\sum \widehat{w}_{i}(\tau)}$ with variance,

$$
\operatorname{Var}\left(\hat{\mu}_{\tau}\right)=\frac{1}{\sum \widehat{w}_{i}(\tau)}
$$

\section{Review Result and Discussion}

\subsection{Technique of Estimating Determinants of Technical Efficiency of Production}

The technique for estimation of the factors affecting the technical efficiency of maize production, which are mostly used by the researchers are reviewed and summarized as follow.

The non-parametric approaches estimation of technical efficiency that is based on linear programming and consists of estimated a production frontier through a convex envelope curve formed by line segments joining observed efficient production units, is used to estimate the factors affecting the technical efficiency of maize production. Using the Tobit regression model with DEA, they have identified the important variables affecting technical efficiency of maize in Wolaita and Gamo Gofa zones [21]. Another author also used two-limit Tobit model they identified the major determinants of technical efficiency of maize production [22]. Even though this method has used in many literatures, it is criticized on four big points as pointed under section 2.2.2.

The parametric approaches estimation of technical efficiency, which enables us to test for the best specification and take measurement errors and random effects into account during estimation of efficiency level of the firm, is mostly used technique of estimating the determinants of technical efficiency of maize production. Maximum Likelihood Estimation for parameters of SPF in determining the major factors affecting the technical efficiency were used [23-26].

In general, both non-parametric and parametric approaches of estimation method can be used to analyze the determinants of technical efficiency.

\subsection{The Factors Affecting Technical Efficiency of Maize Production in Ethiopia}

Many Literatures suggests many factors that affect the efficiency variation of smallholder farmers classifying them into different categories. These (in) efficiency factors are classified into demographic (such as age, family size, etc.), socio-economic (like education, land holding, livestock ownership, off-farm income, etc.), institutional factors (access to credit, Membership of social organization, contact with extension workers, etc.) and physical factor (distance from the nearest market).

I. Demographic Factors
Age: The number of studies result indicated that age of the farm household affects the technical efficiency of maize. Age can serve as a proxy for farming experience and a farmer with older age is expected to have greater farm experience [23]. Another study also supports that age of farm household affects the technical efficiency of maize production in their respective study area $[25,26]$. This may be because of the accumulated experiences that have been gathered over time, they become skillful as they get older and may have an interest in the use of new methods of production.

Family Size: The number of family size in the household is another variable that determines the technical efficiency of maize production as pointed by different researchers. The study shows that the number of family size in household has highly significant impact on TE of maize production [22]. Another study also confirms that the number of family size in the household affects the TE of maize production [24, 25]. A possible reason for this result might be that a larger household size guarantees availability of family labor for farm operations to be accomplished in time. At the time of peak seasons, there is a shortage of labor and hence household with large family size would deploy more labor to undertake the necessary farming activities like ploughing, weeding and harvesting on time than their counterparts and hence they are efficient in maize production.

\section{Socio-Economic Factors}

Land Holding: Land is one among basic economic resources and is primary input to agricultural production influencing farm output in either direction, though the relationship between farm size and technical efficiency is mixed as identified by the most researchers. The link between efficiency and land holding size has been the subject of much discussion in the literature. Various studies have found a small landholding size to have a positive impact on crop level efficiency because of its simplicity in management and less transaction cost compared to the large farm size [21]. Different study carried out also supports that farmers with smaller farms are technically more efficient than farmers with larger operations [23]. On the other hand, several other researchers have found a negative and statistically significant relationship between these two variables because large land holding farmers are more likely to employ modern agricultural practices and hence could be more efficient due to its advantage of the economic scale and scope associated with large farm size [22]. Thus, household with large farm that would have access to credit and better finance more efficiently than their counterpart would.

Education Level of Farmers: Education is a factor that the literature frequently relates to technical efficiency. The variable that has been used in different studies to reflect educational level is the years of schooling of sample farmers. The level of education of household head emerges as an important factor in enhancing efficiencies of maize production [22]. The coefficient of education for Maize farmers also indicates that farmers with greater years of formal education tend to be more efficient technically in Maize production probably due to their enhanced ability to 
acquire technical knowledge, which make them produce closer to the frontier output. A farmer with greater year of schooling tends to be higher efficient in maize production [23, 26, 27].

Off/non-Farm Activities: A number of studies conducted revealed that off/non- farm activities have a systematic effect on the technical efficiency of the farmers. If the farmer is always, out of the farming activity for the search of additional income from these off/non- farm activities [23]. Another explanation may be off-farm income received might not be used for financing the farming activities and the farmers might spent much of their time working off the farm and failing to manage the maize farms properly [25]. Similar finding also indicates that, farmers who participated in offfarm activity were likely to be less efficient in farming as they share their time between farming and other incomegenerating activities [26].

Amount of Livestock Owned: Amount of livestock owned which is a proxy for estimating wealth status of a farmer, also affect the TE in maize production. Farmers who owned a few number of livestock's were technically more efficient than those who owned less number of livestock's in the production of maize. This is because livestock provides a working power (oxen for draught power), manure fertilizer and is a source of income that can be used to purchase the necessary agricultural inputs. Thus, possessing a large number of livestock's is crucial to increase TE in maize production. The amount of livestock owned affects the technical efficiency of maize production in their respective study area $[21,22,25]$.

III. Institutional Factors

Access to Extension Service: Access to extension service is an institutional factor that determine the technical efficiency of maize production as pointed out by most studies. That is, farmers who had more number of extension contact during the production were technically more efficient than those who had less number of extension contact [24]. That is, frequent contact facilitates the flow of new ideas between the extension agent and the farmer, thereby giving a room for improvement in farm efficiency and can help farmers to improve their average performance in the overall farming operation as the service widens the household's knowledge with regard to the use of productivity and input allocation. The studies also confirms that the access to extension service is one factors affecting the TE of maize production in their respective study area [22, 23, 25].

Access to Credit: Credit is another institutional factor that affects the technical efficiency of maize production as identified by most of the researchers. For example, credit availability determines TE of maize production by shifting the cash constraint outwards and enables farmers to make timely purchases of those inputs that they cannot provide from their own sources [24]. Another finding also shows that access to credit decrease the technical inefficiency of maize producing farmers [25].

IV. Physical Factor

Distance to the Nearest Market: It one of the physical factor that affect the TE of maize production as identified. The distance of the farmer's residence from the nearest market, affect the technical efficiency of maize production in the study area $[24,26]$. The possible reason identified by the researchers is as a maize-producing farmers located far from market, there would be limited access to input and output markets and market information and then higher distance to market leads to higher transaction cost that reduces the benefits that accrue to the farmer. Therefore, the distance of the farmer to the nearest market affects the TE of maize production.

\subsection{Random (Mean) Effect Result of the Variables}

The statistical methods, which are random effects models are generally based on collecting the coefficient and standard errors of independent variables that different studies were used and calculated using the method, discussed in section 3.2. The mean effect of variables were given in Table 1 and discussed.

Table 1. Random (Mean) Effect Result of the Variables.

\begin{tabular}{lll}
\hline Variables & Coefficients & Std. Error \\
\hline AGE & $-0.246^{* * *}$ & 0.057 \\
FAMSIZE & $0.020^{* * *}$ & 0.005 \\
EXTENSION & $0.001^{* *}$ & 0.0003 \\
CREDIT & $-0.218^{* * *}$ & 0.010 \\
DISTANCE TO & $0.007^{* *}$ & 0.003 \\
MRKT & $0.020^{* * *}$ & 0.004 \\
LIVESTOCK & 0.012 & 0.009 \\
FARMSIZE & $0.620^{* *}$ & 0.287 \\
OFF FARM & $0.009^{*}$ & 0.005 \\
\hline EDUCATION & \\
\hline
\end{tabular}

Source: Computation from the studies result, 2019

$(* * *, * *$ and $*$ refer to the statistical significance of variables at $1 \%, 5 \%$ and $10 \%$ level of significance, respectively)

The above result showed that, age of the households', family size, access to credit and livestock ownership of the households' are statistically and significantly determine the technical efficiency of maize production in Ethiopia at $1 \%$ significant level. Access to extension service, distance to the nearest market and off farm activity of the farm households' are statistically significant at $5 \%$ significance level. Moreover, the educational level of the farm households' also statistically significant at $10 \%$ significance level in determining the efficiency level of maize production in Ethiopia.

The result also confirms that the above-discussed variables are significantly affect the technical efficiency of maize production in Ethiopia except landholding variable.

\section{Conclusion and Policy Implication}

Ethiopia is an agrarian country where a large majority of the peoples and the poor living in rural areas are deriving their livelihood from this agriculture. Although the transformation towards a more manufacturing and industrially oriented economy is well underway, the 
agriculture sector continues to be the most dominant aspect of the country's economy.

Growth in agriculture from the crop production in which, $50 \%$ of the output of agricultural GDP comes from crop production whereas, $47 \%$ and $3 \%$ are from livestock and forestry respectively.

Even though maize is, one of the cereal crop produced in most part of Ethiopia and has been the leading cereal crop, the studies on the output of maize production in Ethiopia found low efficiency in comparison with the world maize productivity.

In order to improve maize production and productivity, an efficient use of production inputs has to be adopted by smallholder farmers. Thus, raising production levels and reducing its variability are both essential aspects to improve food security and well - being of the people of Ethiopia.

Different studies used different models to analyze the efficiency of farmers and the influence of different agro-climatic and socio-economic conditions on farmers' efficiency.

The result of the review indicate that the considerable factors that affect the efficiency variation of smallholder maize producing farmers are demographic factors (age and family size.), socio-economic factors (education, land holding, livestock ownership, and off-farm income), institutional factors (access to credit, and contact with extension workers) and physical factor (distance from the nearest market).

Therefore, undertaking studies on farm households' efficiencies in different localities help the policy makers and other development workers to design and implement an appropriate policy intervention by focusing on the abovementioned factors in Ethiopia.

\section{References}

[1] CSA (Central Statistical Agency). 2014a. Agricultural sample survey: 2004/5- 2013/14 Volume I: Report on Land Utilization (Private Peasant Holdings, Meher Season). Addis Ababa, Ethiopia.

[2] ATA (Agricultural Transformation Agency). 2014. Annual report transforming agriculture in Ethiopia. Addis Ababa, Ethiopia

[3] CSA (Central Statistical Agency). 2015. Agricultural sample survey. Addis Ababa, Ethiopia.

[4] Hailemariam Leggesse. 2015. Technical efficiency in teff production: the case of Bereh District of Ethiopia. MSc Thesis, Haramaya University, Haramaya, Ethiopia.

[5] CSA (Central Statistical Agency), 2011. Statistical Report on Area and Crop Production, Addis Ababa, Ethiopia.

[6] CSA (Central Statistical Authority), 1989. Agricultural Sample Survey, Report on Farm Management Practices. Addis Ababa.

[7] Alemayehu Seyoum, P. Dorosh, and Sinafkish Asrat, 2012. Food and Agriculture in Ethiopia: Progress and Policy Challenges. University of Pennsylvania Press: Philadelphia Crop Production in Ethiopia: Regional Patterns and Trends.
[8] Rashid, S., 2010. Staple Food Prices in Ethiopia. Paper Prepared for the COMESA policy seminar on Variation in Staple Food Prices: Causes, Consequence, and Policy Options, Maputo, Mozambique, the African Agricultural Marketing Project.

[9] Coelli, T.J. 1995. Recent development in frontier modeling and efficiency measurement. Australian Journal of Agricultural Economics. 39: 219-245.

[10] Bill \& Melinda Gates Foundation, 2010. Accelerating Ethiopian Agriculture Development for Growth, Food Security, and Equity.

[11] Endrias Geta, Ayalneh Bogale, Belay Kassa and Eyasu Elias (2010) Productivity and efficiency analysis of smallholder maize producers in southern Ethiopia, IFPRI.

[12] Shumet Assefa (2012) who is technically efficient in Crop Production in Tigray Region, Ethiopia? Stochastic Frontier Approach, Global Advanced Research Journal of Agricultural Science.

[13] Wagayehu Bekele (2004) Farmerse Preferences for Development Intervention Programs: A Case Study of Subsistence Farmers from East Ethiopian Highlands.

[14] Zenebe, G., A. Oskam, and Tasew, W. (2005). Technical Efficiency of Peasant Farmers in Northern Ethiopia: A Stochastic Frontier Approach.

[15] Alemayehu Seyoum, P. Dorosh and Sinafkish Asrat. 2011. Crop Production in Ethiopia: regional Patterns and Trends Development Strategy and Governance Division, international Food Policy Research institute, Ethiopia Strategy Support Program II, Ethiopia: ESSP Working paper No. 0016

[16] CSA (Central Statistical Agency). 2014. Agricultural sample survey. Addis Ababa, Ethiopia.

[17] Farrell, M.J. 1957. The measurement of productive efficiency. Journal of Royal Statistical Society, Series A, 120: 253-290.

[18] Aigner, D., C. Lovell and P. Schmidt (1977) "Formulation and Estimation of Stochastic Frontier Production Function Models", Journal of Econometrics, 6, 21-37.

[19] Meeusen and J.van den Broeck, 1977. Efficiency estimation from Cobb-Douglas production functions with composed error. International Economic Review, 18: 435-444.

[20] Aigner, D.J. and Chu, S.F. (1968) On Estimating the Industry Production Function. American Economic Review, 58 (4): pp 826-839.

[21] Endrias Geta, Ayalneh Belay, Belay Kasa and Eyasu E. 2013. Productivity and efficiency analysis of smallholder maize producers in southern Ethiopia. D. Agricultural Economics, Haramaya University, Haramaya, Ethiopia.

[22] Sisay Debebe, Jema Haji, Degye Goshu and Endriss, A.k. 2015. Technical, allocative, and economic efficiency among smallholder maize farmers in southwestern Ethiopia: Parametric approach. Journal of development and Agricultural Economics, 7 (8), 282-291.

[23] Getachew Magnar and Bamlak Alamirew. 2014. Analysis of technical efficiency of smallholder maize growing farmers of Horo Guduru Wollega Zone, Ethiopia. Journal of Science, Technology and Arts Research Journal, 3 (3): 204-212. 
[24] Musa Ahmed, Lemma Zemedu and Endrias Geta. 2014. Technical efficiency of maize producing farmers in Arsi Negelle, Central rift valley of Ethiopia. Journal of Agriculture and Forestry, 60 (1): 157-167.

[25] Sorsie, Deme \& Matthews, Nicolette \& Henning, Janus. (2015). Analysis of Factors Affecting Technical Efficiency of Smallholder Maize Farmers in Ethiopia.

[26] Wondimu Tesfaye and Hassen Beshir. 2014. Determinants of technical efficiency in maize production: the case of smallholder farmers in Dhidhessa District of Illuababora Zone, Ethiopia. Journal of Economics and Sustainable Development, 5 (12): 274-284.

[27] Arega D, Rashid M (2005). The efficiency of traditional and hybrid maize production in Eastern Ethiopia: An extended efficiency decomposition approach. J. Afr. Econ. 15 (1): 91116. 